
\title{
R Resercrch Suare \\ The Effect of Rotator Cuff Repair on the Clinical and Psychological Meaningful Improvement in Patients with Rotator Cuff Tear and Insomnia.
}

\author{
Yahui Tong \\ Soochow University \\ Kailun Wu \\ Soochow University \\ An Liu \\ Soochow University \\ Hongxia Zhu \\ Soochow University \\ Huilin Yang \\ Soochow University \\ Jiong Jiong Guo ( $\nabla$ drijguo@163.com ) \\ The First Affiliated Hospital of Soochow University
}

Research article

Keywords: Rotator cuff repair, Insomnia, Clinical outcome, Psychological outcome

Posted Date: July 30th, 2020

DOl: https://doi.org/10.21203/rs.3.rs-49506/v1

License: (1) This work is licensed under a Creative Commons Attribution 4.0 International License.

Read Full License 


\section{Abstract}

Background: Rotator cuff repair is widely used to treat rotator cuff tear, but its impact on the psychological status in patients with rotator cuff tears and insomnia is still poorly understood.

Methods. 240 patients were enrolled who underwent rotator cuff repair at the first affiliated hospital of soochow university from 2014-2018. During the 2-year follow-up period, the patients were assessed preoperatively and postoperatively at 3 months, 6 months, 12 months and 24 months by using Constant, Pittsburgh Sleep Quality Index (PSQI), Insomnia Severity Index (ISI), American Shoulder and Elbow Surgeons' Scale (ASES), Hospital Anxiety and Depression Scale, depression subsection (HADS-D), Hospital Anxiety and Depression Scale, anxiety subsection (HADS-A), and World Health Organization Quality-of-life Scale Abbreviated Version (WHOQOL-BREF).

Results. Finally, a total of 240 patients were enrolled in this study and finished the 2 year follow-up.There were 107 men(43.8\%) and 133 women(56.2\%), and the mean age of the patients was $54.2 \pm 7.5$ years. With the prolongation of postoperative time, pain, activity of daily life, joint mobility and muscle strength were gradually improved from $4.8 \pm 2.2,7.2 \pm 3.4,14.2 \pm 5.5,7.8 \pm 3.5$, and $34.0 \pm 11.3$, respectively, before surgery to $13.2 \pm 3.2,17.8 \pm 2.8,34.0 \pm 6.4,21.0 \pm 4.0$, and $85.9 \pm 12.4$, at 2 years after surgery, which was statistically significant $(P<0.001)$. The scores of ASES and WHOQOL-BREF also increased significantly from $40.5 \pm 9.6,58.3 \pm 8.6$ before operation to $87.7 \pm 10.2,69.3 \pm 7.9$ at two years after operation $(P<0.001)$. HADS-A decreased linearly from $4.8 \pm 2.4$ before operation to $1.4 \pm 1.2$ at two years after operation $(P<0.01)$. The pain scores had a highly positive correlation with the Constant and the ASES scores. The PSQI and the ISI scores had a positive correlation with the HADS-A scores.

Conclusion: For the patients with rotator cuff tears and insomnia, rotator cuff repair may contribute to the improvement of clinical outcome and status of anxiety.

\section{Background}

Rotator cuff tear usually occurred in tennis, backstroke, free stroke, baseball, and other sports that required extreme repeated extension of shoulder, so athletes were the main group of patients in the past. However, in recent years, epidemiological studies suggested that the incidence of rotator cuff tear was almost $17-41 \%$ in the mid and old aged, and was still rising[1].This was related to the aging and the popularity of national fitness in China. With the development of health care, arthroscopic rotator cuff repair has become the "golden standard" for the treatment of rotator cuff tear, which had the advantage of slight injury and few complications[2]. It can make the function of shoulder and persistent pain better[3-6].

At present, most studies confirmed that the rotator cuff repair resulted in improved function and decreased pain[7]. However, the determinants of outcomes measured in these patients should not be limited to aspects of physical health. Persistent pain and insomnia resulting from rotator cuff tear was often accompanied by severe psychological distress, such as depression and anxiety, which was 
associated with poor postoperative outcomes. To some extent, psychological status predicted the outcome after surgery above and beyond prior physical health[8].

The quantity and quality of sleep can be influenced by social, cultural, psychological, and behavioral aspects. For the patients with rotator cuff tear, insomnia is actually quite common and presents a worse perception of quality of life. Psychological distress will be an inevitable result as time passes[8]. It is very difficult to correct anxiety and depressive disorders built up subsequently $[9,10]$. Whereas, psychological distress will induce or exacerbate the original symptoms including insomnia and pain. Then they are trapped in this especially vicious circle. The impact of arthroscopic rotator cuff repair on the vicious circle is still unproven.

Therefore, the purpose of this study aimed to further understand the effect of rotator cuff repair on the clinical and psychological meaningful improvement, particularly in patients with rotator cuff tear and insomnia.

\section{Methods}

\section{Participants}

A retrospective study of arthroscopic rotator cuff repairs performed at the first affiliated hospital of Soochow University from 2014 to 2018 was conducted. All patients were diagnosed as having unilateral rotator cuff tear and diagnosis was based on clinical history, physical examination, and magnetic resonance imaging. All of the rotator cuff tears were insomnic, symptomatic and did not improve after three months of conservative therapy. Our institutional review board approved this study and all patients wrote informed consent.

Inclusion criteria were as follows: (1) unilateral arthroscopic rotator cuff repair; (2) primary rotator cuff repair; and (3) insomnia resulting from rotator cuff tear; (4) a minimum follow-up period of 2 years after the second surgical procedure. They were excluded if (1) partial rotator cuff tears; (2) a history of shoulder surgery for any reason; (3) patients had a psychological disorder before omalgia; and (4) patients who underwent open or arthroscopic partial rotator cuff repairs. Of the 302 patients eligible for this study, 62 were excluded. 27 were lost to follow-up. 18 underwent partial and open rotator cuff repairs. Cuff tears were repaired difficultly with or without severe concomitant lesion, which affected the postoperative outcome, in one patient. Three underwent the reoperation because of retears.

Baseline and follow-up evaluations were performed by a trained research assistant. Demographic data examined included age, sex, side, trauma history, smoking status, PSQI, ISI, tear size and combined lesions. There were 107 men (43.8\%) and 133 women (56.2\%), and the mean age of the patients was $54.2 \pm 7.5$ years. Among them, patients with right shoulder injuries and left shoulder injuries were 140 and 100. The average PSQI score before operation was $7.5 \pm 3.2$, and the average ISI score before operation was $11.8 \pm 8.3$. Other data were shown in Table 1 . 
Table 1

Demographic Data.

\begin{tabular}{|ll|}
\hline Variable & Value \\
\hline No. of patients & 240 \\
\hline Male/female sex & $107 / 133$ \\
\hline Side (right/left) & $140 / 100$ \\
\hline Age, yr & $54.2 \pm 7.5$ \\
\hline Trauma history & 74 \\
\hline Smoking status & 81 \\
\hline PSQI & $7.5 \pm 3.2$ \\
\hline ISI & $11.8 \pm 8.3$ \\
\hline Tear size: cm/>2 cm & $19 / 23$ \\
\hline Combined lesions & \\
\hline Subscapularis tear & 38 \\
\hline AC arthritis & 30 \\
\hline SLAP lesion & 79 \\
\hline Biceps tear & 48 \\
\hline 2 above-mentioned lesions & 32 \\
\hline Abbreviations: PSQI, Pittsburgh Sleep Quality Index; ISI, Insomnia Severity Index; AC, \\
\hline acromioclavicular.
\end{tabular}

\section{Measures}

Pre- and post-operative evaluation included complete documentation of the following clinical and psychological parameters: Constant, Pittsburgh Sleep Quality Index (PSQI), Insomnia Severity Index (ISI), American Shoulder and Elbow Surgeons' Scale (ASES), Hospital Anxiety and Depression Scale, depression subsection (HADS-D), Hospital Anxiety and Depression Scale, anxiety subsection (HADS-A), and World Health Organization Quality-of-life Scale Abbreviated Version (WHOQOL-BREF). All patients were assessed preoperatively and postoperatively at 3 months, 6 months, 12 months and 24 months by an independent healthcare professional not involved in this study.

\section{Constant-Murley Score}


The Constant-Murley Score includes 4 parts: pain degree, daily activity, shoulder joint mobility and muscle strength. Pain level is 15 points, daily activity is 20 points, shoulder joint mobility is 40 points, muscle strength is 25 points, total score is 100 points. As a complex scale, the scale needs to be completed by patients and doctors together. The subjective feelings of patients for their own diseases are evaluated by patients' filling in shoulder pain and its impact on daily activity. By measuring shoulder joint mobility and muscle strength filled in, doctors can objectively reflect patients' limited mobility and the damage caused by pathological changes to muscle strength, so as to comprehensively evaluate the patient's condition.

\section{American Shoulder and Elbow Surgeons' Scale (ASES)}

The ASES is an extensively used questionnaire for the functional evaluation of the shoulder [11]. It contains self-evaluation of patients and objective evaluation of doctors, including pain, activities of daily living, stability, mobility, muscle strength, and so on. The final score needs to be converted into 100 points. The higher the score, the better the function of the shoulder. Scores $\mathbb{7 0}$ indicate poor function.

\section{Pittsburgh Sleep Quality Index (PSQI)}

The PSQI is a self-report questionnaire with 19 items for assessing sleep quality over a 1-month time period[11]. It contains 7 aspects: subjective sleep quality, sleep latency, sleep duration, habitual sleep efficiency, sleep disturbances, use of sleeping medication, and daytime dysfunction. The global score is range from 0 to 21 ; higher scores represent poorer subjective sleep quality. Scores $\leq 5$ indicate good sleep quality, and scores $>5$ indicate poor sleep quality.

\section{Insomnia Severity Index (ISI)}

The scale is a self-report measurement for assessing perceived insomnia severity [12]. It contains 7 items, and $0-4$ scores for each item. The higher the score, the worse the insomnia. The total score is $28,0-7=$ no significant insomnia, 8-14 = sub-insomnia, 15-21 = clinical insomnia (mild), 22-28 = severe insomnia.

\section{Hospital Anxiety and Depression Scale (HADS)}

The HADS comprises 14 items: 7 items measure symptoms of anxiety (HADS-A) and 7 items measure symptoms of depression (HADS-D) [13]. Each item is scored from 0 to 3 , and each subscale is scored from 0 to 21. The severity of depression or anxiety is classified as follows: normal range: $0-7$; mild symptoms: 8-10; moderate symptoms: $11-15$; severe symptoms: $16-21$. The validity of the scale has been demonstrated in different countries.

\subsubsection{World Health Organization Quality-of-life Scale Abbreviated Version (WHOQOL-BREF)}

The scale consists of 26 items, which are divided into four fields:physical, psychological, social relationships, environment [14]. The higher the score, the better the quality of life.

\section{Statistical Analysis}

Data analysis was performed with SPSS19.0 statistical software (IBM Corp., Armonk, NY, USA). 
The paired t-test and chi-square test were used for single-factor analysis, and repeated-measures analysis of variance (ANOVA) was used to analyze measurements including Constant, PSQI, ISI, ASES, HADS-D, HADS-A, and WHOQOL-BREF. The Pearson correlation was used to analyze the correlation between outcome measurements (Constant, ASES, HADS-D, HADS-A, and WHOQOL-BREF) and variables such as Constant (pain), PSQI, and ISI. A $p$ value of $<0.05$ was considered statistically significant.

\section{Results}

With the prolongation of postoperative time, pain score, activity of daily life score, shoulder mobility score, muscle strength score and total score of Constant-Murley scale increased linearly, indicating that pain, activity of daily life, joint mobility and muscle strength were gradually improved, which was statistically significant $(p<0.001)$. The scores of ASES and WHOQOL-BREF also increased significantly from $40.5 \pm 9.6,58.3 \pm 8.6$ before operation to $87.7 \pm 10.2,69.3 \pm 7.9$ at two years after operation $(p<$ $0.001)$. HADS-A decreased linearly from $4.8 \pm 2.4$ before operation to $1.4 \pm 1.2$ at two years after operation $(p<0.01)$. There was no significant change in HADS-D score during the 2 -year follow-up period $(p>0.05)$ (Table 2). As time passed, PSQI and ISI scores showed a linear downward trend, indicating that the sleep quality was gradually improved, and the variation at 3 months after surgery was greater than that in other months (Fig. 1 ).

Table 2

Serial changes in psychological and outcome measurements after rotator cuff repair.

\begin{tabular}{|c|c|c|c|c|c|c|}
\hline \multirow[t]{2}{*}{ Measurement } & \multirow{2}{*}{$\begin{array}{l}\text { Before } \\
\text { surgery }\end{array}$} & \multicolumn{4}{|c|}{ After surgery } & \multirow[t]{2}{*}{$p$ value } \\
\hline & & $3 \mathrm{mo}$ & $6 \mathrm{mo}$ & $12 \mathrm{mo}$ & $24 \mathrm{mo}$ & \\
\hline Constant, pain & $4.8 \pm 2.2$ & $7.7 \pm 4.5$ & $10.0 \pm 3.0$ & $12.8 \pm 3.4$ & $13.2 \pm 3.2$ & $\otimes 0.001^{*}$ \\
\hline Constant, activity & $7.2 \pm 3.4$ & $9.3 \pm 4.8$ & $13.5 \pm 3.1$ & $16.2 \pm 3.0$ & $17.8 \pm 2.8$ & $\otimes 0.001^{\star}$ \\
\hline $\begin{array}{l}\text { Constant, } \\
\text { mobility }\end{array}$ & $14.2 \pm 5.5$ & $21.7 \pm 8.1$ & $26.3 \pm 6.5$ & $31.1 \pm 6.2$ & $34.0 \pm 6.4$ & $\otimes 0.001^{\star}$ \\
\hline $\begin{array}{l}\text { Constant, } \\
\text { strength }\end{array}$ & $7.8 \pm 3.5$ & $11.2 \pm 5.6$ & $17.2 \pm 5.2$ & $19.7 \pm 3.8$ & $21.0 \pm 4.0$ & $\otimes 0.001^{\star}$ \\
\hline Constant, total & $34.0 \pm 11.3$ & $\begin{array}{l}50.0 \pm \\
16.6\end{array}$ & $\begin{array}{l}66.9 \pm \\
13.5\end{array}$ & $\begin{array}{l}79.8 \pm \\
12.0\end{array}$ & $\begin{array}{l}85.9 \pm \\
12.4\end{array}$ & $\otimes 0.001^{\star}$ \\
\hline ASES & $40.5 \pm 9.6$ & $\begin{array}{l}59.6 \pm \\
14.3\end{array}$ & $\begin{array}{l}71.4 \pm \\
10.7\end{array}$ & $\begin{array}{l}83.2 \pm \\
11.1\end{array}$ & $\begin{array}{l}87.7 \pm \\
10.2\end{array}$ & $\otimes 0.001^{\star}$ \\
\hline HADS-D & $3.9 \pm 1.7$ & $3.0 \pm 2.1$ & $2.2 \pm 1.1$ & $1.5 \pm 1.0$ & $1.2 \pm 0.8$ & 0.075 \\
\hline HADS-A & $4.8 \pm 2.4$ & $3.8 \pm 3.3$ & $2.5 \pm 1.9$ & $1.7 \pm 1.3$ & $1.4 \pm 1.2$ & $0.008^{*}$ \\
\hline WHOQOL-BREF & $58.3 \pm 8.6$ & $\begin{array}{l}61.7 \pm \\
11.0\end{array}$ & $\begin{array}{l}65.1 \pm \\
10.3\end{array}$ & $68.0 \pm 8.2$ & $69.3 \pm 7.9$ & $0.021^{*}$ \\
\hline
\end{tabular}


In Pearson correlation coefficient analysis, the pain scores had a highly positive correlation with the Constant and the ASES scores. The PSQI and the ISI scores had a positive correlation with the HADS-A scores. There was no correlation between pain scores and HADS-D, HADS-A or WHOQOL-BREF scores. The PSQI and ISI scores had no correlation with the Constant, ASES, HADS-D, and WHOQOL-BREF scores. (Table 3)

Table 3

Correlation between variables and postoperative outcome measurements

\begin{tabular}{|llllll|}
\hline Variable & Constant & ASES & HADS-D & HADS-A & WHOQOL-BREF \\
\hline Constant, pain & $0.76^{*}$ & $0.62^{*}$ & -0.14 & -0.29 & 0.37 \\
\hline PSQI & -0.21 & -0.16 & 0.21 & $0.49 *$ & -0.23 \\
\hline ISI & -0.20 & -0.18 & 0.28 & $0.45^{\star}$ & -0.25 \\
\hline $\begin{array}{l}\text { *Pearson correlation coefficient }(r) \otimes 0.40 \text { was considered satisfactory (rख0.80 excellent, } 0.61-0.80 \text { very } \\
\text { good, 0.41-0.60 good, 0.21-0.40 fair and 0-0.20 poor correlation. }\end{array}$ \\
\hline
\end{tabular}

\section{Discussion}

Current studies focused on the improvement of function and the relief of pain too much for postoperative patients rather than psychological status and HRQoL (Health Related Quality of Life). However, patientcentered subjective feeling and quality of life were more meaningful for the rotator cuff tears. Several studies also suggested that intense psychological distress may lead to dissatisfaction for treatment and disturb postoperative recovery in major orthopaedic procedures $[15,16]$. More recently, expectations and psychological predisposition have been discussed as the determinants of postoperative efficacy $[15,16]$. But psychological status of the rotator cuff tears are given neither the attention nor the prominence they deserve, especially for those suffering from insomnia.

Insomnia is a common complaint of patients with rotator cuff tears. In the study reported by Austin et al. [17], patients with symptomatic rotator cuff tears, the incidence of insomnia is 3 to 6 -fold more common than in the general public. Inadequate and restless sleep, along with severe pain, is often a major contributor for them to face surgeries with determination. On the one hand, long-term sleep disturbance caused by pain will result in psychological distress, including anxiety and depression. On the other hand, mental problems will, in turn, exacerbate subjective symptoms and induce intractable insomnia that fails to respond to medications. In our study, there was a significant improvement in sleep until 6 months postoperatively, which was in accordance with other reports $[18,17]$.

In terms of psychological status, HADS-D and HADS-A were used as evaluation parameters in our series. The number of people with anxiety and depression (HADS-A or HADS-D score $\geq 8$ points) was 15 and 7 , accounting for $6 \%$ and $3 \%$ respectively. It showed that the rotator cuff tears with insomnia do have psychological problems such as anxiety and depression, which was a quite common condition. Through the implementation of arthroscopic rotator cuff repair, it was found that the joint function, the sleep 
quality, the anxiety situation and the quality of life of patients has been significantly improved during the 2-year follow-up. But the impact on depression was not significant, which was consistent with the study of Cho $C$ et al [19]. and Kennedy $P$ et al.[20]. However, in Pearson correlation analysis, we found that there was a positive correlation between sleep disorder scores (PSQI and ISI) and anxiety scores, indicating that with the improvement of sleep quality, the anxiety status of patients will also be improved. To our surprise, data showed the weak correlation between relief of pain and psychological status. This finding suggested that anxiety was likely multifactorial and not simply a product of night pain. To some extent, sleep disorder at least have a stronger influence on anxiety for the rotator cuff tears. However, sleep status had no significant effect on shoulder joint function and quality of life.

The first limitation of the current study was the lack of a control group who had not undergone rotator cuff repair, which has the potential to produce prejudiced outcomes. Secondly, the influence factors for psychological status are very complex, including chronicity of the tear, social condition, literacy level and family background. In fact, it is very hard to determine what changes the psychological status. Therefore, the selection of patients in this study could be biased. Thirdly, our findings cannot explain the improvement of WHOQOL-BREF. This still needs further studies.

The results of our study indicate that rotator cuff repair can improve clinical outcome, as well as psychological status in patients with rotator cuff tear and insomnia. Rotator cuff repair also may mitigates sleep disturbance indirectly by alleviating pain.

\section{Conclusions}

The determinants of outcomes in patients with rotator cuff tear and insomnia are composed of the clinical outcome (pain, shoulder function, quality of life) and psychological status. Arthroscopic rotator cuff repair cannot only improve the clinical outcome, but also anxiety. Moreover, the improvement of insomnia is crucial to alleviating patients' anxiety after surgery. But insomnia cannot be used as an indicator to predict the clinical outcome.

\section{Abbreviations}

ASES, American Shoulder and Elbow Surgeons' Scale; HADS-D, Hospital Anxiety and Depression Scale, depression subsection; HADS-A, Hospital Anxiety and Depression Scale, anxiety subsection; WHOQOLBREF = World Health Organization Quality-of-life Scale Abbreviated Version; PSQI, Pittsburgh Sleep Quality Index; ISI, Insomnia Severity Index.

\section{Declarations}

\section{Funding}

None. 
Availability of data and materials

The data supporting the conclusions of this article is included within the article.

\section{Authors' contributions}

YT and AL collected, analyzed, and interpreted the data and wrote the paper. HZ, HY and JJG were involved in the study design and conception and in critically reviewing and revising the article content. $\mathrm{KW}$ and $\mathrm{AL}$ collected, analyzed, and interpreted the data. All authors read and approved the final manuscript.

\section{Ethics approval and consent to participate}

This study has been approved by the research ethics committee of the First Affiliated Hospital of Soochow University. Written informed consent was obtained from the patient for publication of this study

\section{Consent for publication}

Not applicable.

\section{Competing interests}

The authors declare that they have no competing interests.

\section{Author details}

Department of Orthopedics, The First Affiliated Hospital of Soochow University『Suzhou, China.

\section{References}

1. Endo A, Suzuki M, Akagi A, Chiba N, Ishizaka I, Matsunaga A, et al. Reliability and validity of the upper-body dressing scale in Japanese patients with vascular dementia with hemiparesis. OCCUP THER INT. 2015;22(1):10 - 8. 'doi:'10.1002/oti.1378.

2. Randelli P, Bak K, Milano G. State of the art in rotator cuff repair. Knee Surgery, Sports Traumatology, Arthroscopy. 2015;23(2):341-3. 'doi:'10.1007/s00167-015-3515-x.

3. Stuart KD, Karzel RP, Ganjianpour M, Snyder SJ. Long-Term Outcome for Arthroscopic Repair of Partial Articular-Sided Supraspinatus Tendon Avulsion. Arthroscopy: The Journal of Arthroscopic \& Related Surgery. 2013;29(5):818 - 23. 'doi:'10.1016/j.arthro.2013.02.004.

4. McCormack RA, Shreve M, Strauss EJ. Biologic Augmentation in Rotator Cuff Repair-Should We Do It, Who Should Get It, and Has It Worked? Bulletin of tbe. Hospital for Joint Diseases. 2014;72(1):8996.

5. Spennacchio P, Banfi G, Cucchi D, Ambrosi D, Cabitza R, Randelli P P. Long-term outcome after arthroscopic rotator cuff treatment. Knee Surgery, Sports Traumatology, Arthroscopy. 2015;23(2):523- 
9. 'doi:'10.1007/s00167-014-3234-8.

6. Schmidt CC, Jarrett CD, Brown BT. Management of Rotator Cuff Tears. The Journal of Hand Surgery. 2015;40(2):399-408. 'doi:'10.1016/j.jhsa.2014.06.122.

7. Stone MA, Ho JC, Kane L, Lazarus M, Namdari S. Midterm outcomes of arthroscopic rotator cuff repair in patients aged 75 years and older. J SHOULDER ELB SURG. 2020;29(7):S17-22.

'doi:'10.1016/j.jse.2019.11.022.

8. Cho C, Seo H, Bae K, Lee K, Hwang I, Warner JJP. The impact of depression and anxiety on selfassessed pain, disability, and quality of life in patients scheduled for rotator cuff repair. J SHOULDER ELB SURG. 2013;22(9):1160-6. 'doi:'10.1016/j.jse.2013.02.006.

9. Yakupov EZ, Troshina YV. Anxiety, insomnia, depression - in conjunction with or opposite to functional disorders. Zhurnal nevrologii i psikhiatrii im. S.S. Korsakova. 2016;116(5):119. 'doi:'10.17116/jnevro201611651119-124.

10. Gebara MA, Siripong N, DiNapoli EA, Maree RD, Germain A, Reynolds CF, et al. Effect of insomnia treatments on depression: A systematic review and meta-analysis. DEPRESS ANXIETY. 2018;35(8):717 - 31. 'doi:'10.1002/da.22776.

11. Piitulainen K, Paloneva J, Ylinen J, Kautiainen $H$, Häkkinen A. Reliability and validity of the Finnish version of the American Shoulder and Elbow Surgeons Standardized Shoulder Assessment Form, patient self-report section. BMC MUSCULOSKEL DIS. 2014;15(1):272. 'doi:'10.1186/1471-2474-15272.

12. Castronovo V, Galbiati A, Marelli S, Brombin C, Cugnata F, Giarolli L, et al. Validation study of the Italian version of the Insomnia Severity Index (ISI). NEUROL SCI. 2016;37(9):1517-24. 'doi:'10.1007/s10072-016-2620-z.

13. Bocéréan C, Dupret E. A validation study of the Hospital Anxiety and Depression Scale (HADS) in a large sample of French employees. BMC PSYCHIATRY. 2014;14(1):354. 'doi:'10.1186/s12888-0140354-0.

14. Min SK, Kim KI, Lee Cl, Jung YC, Suh SY, Kim DK. Development of the Korean Versions of WHO Quality of Life Scale and WHOQOL-BREF. QUAL LIFE RES. 2002;11(6):593-600. 'doi:'10.1023/A:1016351406336.

15. Blackburn J, Qureshi A, Amirfeyz R, Bannister G. Does preoperative anxiety and depression predict satisfaction after total knee replacement? The Knee. 2012;19(5):522-4. 'doi:'10.1016/j.knee.2011.07.008.

16. Perruccio AV, Davis AM, Hogg-Johnson S, Badley EM. Importance of self-rated health and mental well-being in predicting health outcomes following total joint replacement surgery for osteoarthritis. ARTHRIT CARE RES. 2011;63(7):973 - 81. 'doi:'10.1002/acr.20467.

17. Austin L, Pepe M, Tucker B, Ong A, Nugent R, Eck B, et al. Sleep Disturbance Associated With Rotator Cuff Tear. Arthroscopy the Journal of Arthroscopic Related Surgery. 2014;30(6):e16-7. 'doi:'https://doi.org/10.1016/j.wem.2015.06.006. 
18. Serbest S, Tiftikçi U, Askın A, Yaman F, Alpua M. Preoperative and post-operative sleep quality evaluation in rotator cuff tear patients. Knee Surgery, Sports Traumatology, Arthroscopy. 2017;25(7):2109-13. 'doi:'10.1007/s00167-016-4228-5.

19. Cho C, Song K, Hwang I, Warner JJP. Does Rotator Cuff Repair Improve Psychologic Status and Quality of Life in Patients With Rotator Cuff Tear? Clinical Orthopaedics and Related Research®. 2015;473(11):3494 - 500. 'doi:'10.1007/s11999-015-4258-1.

20. Kennedy P, Joshi R, Dhawan A. The Effect of Psychosocial Factors on Outcomes in Patients With Rotator Cuff Tears: A Systematic Review. Arthroscopy: The Journal of Arthroscopic \& Related Surgery. 2019;35(9):2698 - 706. 'doi:'10.1016/j.arthro.2019.03.043. 